\title{
The Bangkok Land Information System Project - Designing an Integrated Land Information System for a Large City in the Developing World
}

Ian P. Williamson

Professor of Surveying and Land Information

The University of Melbourne

Senior Adviser, BLIS Project

and

Garry Mathieson

LIS Adviser, BLIS Project

\begin{abstract}
International aid and lending organisations worldwide are increasingly recognising the importance of improving the operation and management of cities in developing countries. A key activity to improve these cities is land information management, however the methods adopted in the developed countries are not necessarily applicable to those which are less developed. This paper reviews an important and innovative approach to developing a land information system for the City of Bangkok. The Bangkok Land Information System (BLIS) Project is a cooperative effort between five key authorities in the City; this cooperation in itself is almost unique. The paper reviews the operation of and strategy behind the design of the two year BLIS project and highlights some of the early lessons.
\end{abstract}

\section{INTRODUCTION}

There is increasing recognition that cities are the economic engines of developing countries. For example, approximately $60 \%$ of GNP of developing countries comes from urban areas even though these areas contain only about one third of the total population in such countries. As well urban areas account for approximately $80 \%$ of GNP growth in developing countries. Over the past three or four decades, urban population in the developing countries has increased from less than 300 million to about 1.3 billion today. In 1989 the urban population in developing countries will increase by some 45-50 million as compared to 7-8 million in developed countries. By the year 2000, cities and towns in the developing world will have to absorb another 600-700 million people or about two thirds of the world's total population increase (World Bank, 1989).

Despite progress in some areas, the urban environment continues to deteriorate in most developing countries. The managers of cities are trying a whole range of techniques to improve the quality of life and are "running harder and faster than ever", but they are continuing to slip further behind. This is evident from the rapid expansion of informal settlements with poor infrastructure facilities and dilapidated houses. Other signs include increasing congestion, air and water pollution, and deteriorating infrastructure. The rapid urbanisation has outstripped many, if not most, governments' ability to cope with even the most basic of services. As a consequence, the major international aid and lending organisations, and its borrowers, have to tackle the serious distortions which exist in the financial, land and housing markets (Holstein, 1990 and Williamson, 1991).

There are large inequities in most cities in developing countries where, as a consequence of poor mapping and land administration systems, a large number of well developed properties are not paying essential 
taxes. If the city does not have an up-to-date record of property, does not know where it is, who owns it and it's value, it is difficult to tax land and property equitably. At the same time, if a city does not know the location of all existing services, it is difficult to repair and upgrade them. Other consequences of poor land management include the inability to undertake any city planning or acquire land for public facilities. Land and geographic information systems are seen as one method of helping overcome these urgent problems. Examples of large metropolises in developing countries which are creating various LIS/GIS/FIS systems include Cairo (Leppanen, 1990), Mexico City (Reyes et al, 1990) and Bangkok .

The City of Bangkok is an excellent case study to examine the problems and strategies in developing an integrated land information system. First, the Bangkok Land Information System (BLIS) Project builds on the success of the larger Royal Thai Government/World Bank/Australian funded Thailand Land Titling Project since 1983. This project has the objective of upgrading the cadastral mapping base, improving the land titles records and improving the valuation base for the City. Secondly, the BLIS Project is an ideal example of a strategy to develop a land information system in a large metropolis in a developing country. One of the most important aspects of this project is the institutional arrangements for its establishment and management. The project exhibits an exceptionally high level of cooperation and collaboration between the key participating agencies including the Bangkok Metropolitan Administration (BMA), the Metropolitan Water Authority (MWA), the Metropolitan Electricity Authority (MEA), Telephone Organisation of Thailand (TOT) and the Department of Lands (DOL). Each of these organisations has invested money and people into the joint project. The project is also being supported by the Australian International Development Assistance Bureau (AIDAB).

There is often confusion with the terminology used in land and geographic information system projects however in this case the terminology is quite clear. The overall project is called the Bangkok Land Information System (BLIS) Project. This is justified since the project is primarily large scale $(1: 1,000)$ with a large parcel-based component. BLIS is very much a dynamic land administration system. A major component of the project is a Digital Mapping Base including both topographic and parcel information. An important component of the project will be the development of specific Facility Information Systems for the major utilities involved in the project. All the preceding mapping will be displayed at a nominal scale of 1:1,000. A subset of the BLIS Project will be the development of a Geographic Information System to be used for small scale planning, demographic, transportation and statistical purposes. The data will be based on an existing 1:10,000 map and will be displayed at this nominal scale.

\section{THE CITY OF BANGKOK}

Bangkok Metropolis, the capital of Thailand, is located on a low flat plain of the Chao Phraya River extending to the Gulf of Thailand. Since established in 1782 as the new capital of Thailand, Bangkok Metropolis has been promoted as the centre of commerce, industry, national culture, national and international transportation and most of the central government administration. The total area of the Metropolis now covers 1568 square kilometres.

Bangkok grew slowly up until 1900, when the population was only 600,000. After the Second World War, the city experienced heavy public investment in national infrastructure and public utilities throughout the city. The rate of growth in population and the urbanised area has steadily increased since that time.

Although an official figure from the household registrations in 1989 showed Bangkok's population at 5.8 million, it is generally recognised that with at least $30 \%$ of persons not registered and with the uncontrollable, one way migration from the rural areas, the actual population now totals over 10 million, making it one of the World's largest cities.

The Bangkok Metropolitan Administration, with staff numbers in excess of 40,000, is responsible for such services as Flood Protection, Drainage and Sewerage, City Planning, Public Works and Traffic Control, Medical and Health Services, Social Welfare and Community Development, Education and Public Cleanliness and Orderliness. Other major utility services are provided by the Telephone Organisation of 
Thailand, Metropolitan Waterworks Authority, and the Metropolitan Electricity Authority .

Up to 1990 the Thai economy experienced its third year of double digit-growth and is expected to grow at annual rates of around $8 \%$ during the next ten years. In view of this rapid growth and industrialisation, the recent demand for public services and infrastructure has pushed the city government's ability to provide these services to the limit. Traffic congestion, water shortages, solid waste, and air, water and noise pollution problems have noticeably worsened in the last few years of the rapid industrialisation. These problems are now acute, as nearly $75 \%$ of Thailand's manufacturing is concentrated in the Bangkok area. Bangkok's growth and the subsequent problems being experienced by the servicing authorities in attempting to respond to this expansion in terms of the planning and supply of services can be illustrated by the following examples:-

\section{a. Water Supply Shortages}

The MWA has experienced an increased demand for its water over the past decade of approximately $8 \%$ per annum. Despite considerable expansion of its distribution system, the MWA is able to supply only $43 \%$ of the area and $66 \%$ of the population under its responsibility; the rest is met by ground water pumping. Officials expect the demand for water to double in 10 years and more than triple in 16 years; outpacing a supply which faces limited raw water allocation, water pollution and rising supply costs. In order to supplement pipe water in some areas, excessive ground water pumping has led to land subsidence of 5-10 centimetres per year, affecting an area of 4,550 square kilometres and contributing to flood damage equal to billions of baht per year (US\$1 $=25$ baht approximately).

\section{b. Building Construction Activity}

First class residential condominiums, office buildings, hotels, and shopping centres are empirical evidence of intensive land development and economic growth, especially in the central areas of Bangkok. Due to the growth of the overall economy and foreign investments, the demand for office space alone will see the current stock as of 1989 more than double by 1993. Construction activity within Bangkok has recorded a big increase over recent years with the demand for construction permits alone from the BMA increasing in 1989 by $34 \%$ over 1988. It is acknowledged that the BMA is unable to control construction growth as there is no City Plan currently in existence as the first plan drafted in 1960 was not enforced. In addition, the 1979 Building Control Act does not deal with building numbers or heights.

c. Telephone Installations

Despite recently announced plans for a three million line phone expansion project, the TOT has currently 800,000 subscribers on the waiting list for installation of phones and the annual demand for phones is rising by an average $15 \%$ per year. Waiting periods for the installation of phones can currently be up to seven years, largely due to the lack of cable lines to connect to the subscribers' buildings.

\section{d. Waste Water Treatment}

By 1994, the BMA will have completed the construction of five water treatment plants in a major step towards water treatment and pollution control of the city's waterways. Nevertheless, these plants will be capable of treating only one quarter of Bangkok's waste water.

e. Motor Vehicles and Traffic Problems

The number of cars on the streets of Bangkok has doubled over the past ten years and passed the 2 million mark during 1989. Inadequate road space is normally blamed for the traffic jams since Bangkok has a total road surface equivalent to $8 \%$ of the city area - for most major cities, $20-25 \%$ 
is the norm. The uncontrolled growth, the lack of City Planning and the increased demand for private cars in Bangkok brought about by the economic boom, have made the current traffic problems intolerable. Air pollution in traffic choked areas is well above recognised danger levels and last year over one million residents suffered from respiratory diseases. Several major mass transit projects are currently being evaluated.

\section{f. Land Development Boom}

Land prices have dramatically increased since 1987 as land within a $60 \mathrm{~km}$ radius of Bangkok could be profitably converted for urban, commercial, resort or industrial uses in preference to agricultural uses. The Department of Lands experienced a four fold increase in ownership transfers from 1987 to 1990. During the first three quarters of fiscal year 1990, ownership transfers increased $70 \%$ over the same period of the previous year. However, due to lack of planning, of the total 1,560 sq km of land in Bangkok, there exists a large amount of inner-city land left undeveloped or underdeveloped, resulting in inefficient land uses and haphazard growth in other areas.

\section{HISTORY OF THE BLIS PROJECT}

For nearly a decade the BMA in particular, has recognised the need to establish some form of Land Information System (LIS) for the City of Bangkok to help overcome the ever increasing problems facing the City.

Many countries have provided technical assistance in the area of LIS to the BMA and other utility authorities in Bangkok over the past six years. The history of BLIS has included assistance from the governments of Belgium, Germany, Japan, France, Canada and Australia. Assistance has taken the form of base mapping, pilot projects, study tours and seminars.

Within the BMA, the BLIS concept is accepted and supported at the most senior administrative and political levels. This support culminated in an agreement being reached between the BMA, the major utility authorities and the Department of Lands in early 1988 to set up a pilot project and allocate the necessary funds for the purchase of equipment to support the project. The original Memorandum of Understanding outlined the joint cooperation agreement for the establishment and use of the BLIS (Phase I) between the BMA, DOL, MWA, MEA and TOT. Each organisation has contributed to the acquisition of the hardware and software, and has contributed staff for the duration of the project. The hardware/software/maintenance/training for the project cost approximately US\$1 million with the organisations providing about 20 professional staff. The BMA has provided all office and support facilities. The Australian Government, through the Australian International Development Assistance Bureau (AIDAB), has provided approximately US\$0.5 million for technical advice.

Due to the significant commitment of the participating authorities in BLIS in terms of capital expenditure, staff commitments to the Project and the degree of cooperation, this Project is naturally seen as providing a considerable focus for the development and implementation of LIS/GIS strategies for the Royal Thai Government.

Regular Project Sub-committee and Steering Committee meetings are significant in that they are attended by Senior Officials of all the participating agencies including the Royal Thai Survey Department. This provides an excellent forum for discussion and information dissemination regarding the Project and related issues throughout the Royal Thai Government.

\section{OBJECTIVES OF THE BLIS PROJECT}

As stated above, the City of Bangkok has had many consultants undertake studies to determine an appropriate strategy to develop a land information system for the City. There was one fundamental weakness in all these studies. They were all done by overseas advisers or organisations under a variety of international aid programs. None of the studies were undertaken by the Thai organisations themselves 
although they fully cooperated in the studies. The overseas organisations came into the country, did their study, prepared a report and left. Even though little of the experience of these LIS studies remained in Thailand, the studies were critical in raising the level of interest and commitment for BLIS.

Due to the magnitude of the problems in Bangkok and the resulting size and complexity of any proposed land information system, the key Thai organisations in the City of Bangkok came together to undertake their own study and pilot project called the Bangkok Land Information System Project (BLIS). The overriding objective of the BLIS project was for the relevant Thai organisations to gain experience in designing and building their own systems.

The primary objectives of the BLIS Project are as follows:

(a) Education, training and the gaining of experience of Thai Government officers in the key organisations required to establish a future computerised land information system for the City of Bangkok. While the pilot project itself will significantly meet this objective in the short term, it was quickly realised that education and training of staff in all the relevant organisations would also be a key in the long term success of BLIS. As a consequence the project will have to assist in the development of a ten year education and training strategy for the introduction of LIS/GIS. Such a strategy will require a major input from the academic institutions already involved in LIS/GIS in Thailand, such as the Department of Surveying Engineering at Chulalongkorn University. In addition it will certainly require short, medium and long term programs both in Thailand and overseas.

(b) The determination of an appropriate common base map for the City of Bangkok which could be used by all organisations which will be developing land information systems in the City. Without doubt this is the most important technical objective of the project. Thailand had recognised the importance of cooperation in developing a LIS for the City. Senior Thai Government officials had visited Australia, Canada, Sweden, Germany and France and seen the importance of such cooperation. Even though the necessary cooperation between agencies in all these countries is not always the case, the Thai officials and all the overseas studies emphasised the importance of one common base map and a cooperative effort in developing such a map.

(c) The determination of an achievable long term strategy for the development of BLIS. From the overseas studies, from visits, from attending conferences and from LIS/GIS vendors, the Thai officials have seen many highly developed and complex systems. The big question in the City of Bangkok was to determine what is possible and what are the priorities in establishing a LIS for the City. Simply, many of the systems and approaches put forward from developed countries may not be applicable to a rapidly expanding city of about ten million inhabitants in developing countries. The project has a clear objective of determining what is possible. The long term strategy will address such questions and issues as:

- how should the base map be prepared,

- who should prepare it,

- who should manage the updating of the map,

- who should pay for the preparation and updating of the map,

- what should be included in the base map. Should it only be topographic data or should it also contain land parcel data? Should it contain all buildings,

- should any attribute data be included on the base map,

- should the private sector be involved in the preparation of the base map

- what are the priorities in developing the LIS, and

- what institutional arrangements should be put in place to facilitate and encourage coordination when each authority wishes to develop it's own system in house?

There is a clear recognition with the Thai officials that if the system gets too complex it has little chance of success.

Tied closely to the development of a long term strategy is the determination of the structure of a future 
LIS. It is important to remember that there are a large range of data gathers and data users in the proposed system all of which have different needs. For example the utility authorities are not particularly interested in the land tenure and land parcel base. They wish to have a map of all the roads and buildings so they can show their services and customers. On the other hand parcel information is essential for land tax and planning, although a considerable amount of tax is raised from levies on buildings. All these activities are at a nominal scale of 1:1,000 however there is an increasing awareness in the BMA Policy and Planning Department of the need for a smaller scale GIS based on an existing 1:10,000 scale map series.

Secondary benefits of the project include:

a. The establishment of an operational pilot land information system for the City of Bangkok.

b. Improved record keeping systems for land related information.

c. A better understanding of the existing land information processes in the respective authorities.

d. A significant contribution to the improvement of the effectiveness and operation of the participating authorities.

e. The determination of the level of technology and sophistication required for the establishment of a LIS for the City of Bangkok. It will be important to evaluate software and hardware maintenance and the reliability of the systems in Bangkok. This experience is very valuable for the future.

The Thai Government Steering Committee for the BLIS Project realised that in the short term there was not sufficient experience in Thailand to undertake the pilot project. As a consequence Thailand asked for assistance from the Australian International Development Assistance Bureau. The assistance provided is a full-time Land Information System Adviser for two years provided by the Overseas Projects Corporation of Victoria (OPCV) and a Senior Adviser and Project Coordinator on a part-time basis provided by the consulting arm of The University of Melbourne (UNIMELB). These advisers are not undertaking nor managing the BLIS Project. They are simply drawing on their experience in establishing similar systems in Australia and overseas to give advice where required.

The over-riding success of the project to date is the recognition that a LIS for the City of Bangkok will only be possible if the key agencies cooperate and coordinate their activities. This is a lesson that many other countries in both the developed and developing world should heed.

\section{LINKS BETWEEN BLIS AND TLTP}

The Thailand Land Titling Project (TLTP) is an important initiative in Thailand which has had a major influence on the establishment of BLIS and has played a central role in establishing the topographic and parcel base map for BLIS (Williamson, 1984; Angus-Leppan and Williamson, 1985; Angus-Leppan, 1988; Smith and Holstein, 1987; Williamson, 1990). The TLTP is a major land administration project spanning 20 years which has the objectives of issuing land titles to all freehold and government lands in Thailand, of improving the efficiency of land administration in both rural and urban areas of Thailand and of establishing an equitable land valuation system for Thailand. The project involves over 20 million land parcels, which is about three times the number of land parcels in Australia for example. The project is administered by the Department of Lands and is co-financed by the World bank and AIDAB.

A major component of the TLTP is to prepare up-to-date land parcel maps for Bangkok based on large scale $(1: 1,000)$ aerial photomaps, together with the relevant parcel data including valuation data provided by the new Central Valuation Office (CVA). This parcel data, together with the photomaps, will form an important part of the base data for BLIS. Without this data it would be very difficult to establish BLIS in the proposed form.

Approximately 2,000 Cadastral Index maps within Bangkok Metropolis have been produced at the end of the first stage of the Project i.e. 1990.

In accordance with the Sixth National Plan for Thailand (1989-1994), the second phase of the TLTP will have a major emphasis on the development of a national strategy for land information systems at the 
parcel level. In addition Phase II will complete the urban mapping of Bangkok by 1993. The LIS initiatives in DOL will, and must be, intimately linked to the development of BLIS. The urban mapping program, the development of computerised indexes and the provision of valuation data are central to BLIS and must be closely coordinated with DOL.

The development of BLIS is a major outcome of the TLTP to a significant extent. Since it is an application of the base data of the TLTP, it could have a greater profile than the TLTP in a broad range of areas ranging from planning, utility management, emergency services and transportation.

\section{THE BLIS PROJECT}

\subsection{Management Structure}

The overall responsibility of the BLIS Project is by an inter-agency Executive Committee comprising elected officials and chaired by the Deputy Governor, BMA. This committee meets annually or as required. Policy and major administrative issues are made by the inter-agency Steering Committee which meets quarterly or as required. It comprises senior bureaucrats and is chaired by the BLIS Project Director, the Director General of the Department of Policy and Planning, BMA. Day to day responsibility for the Project rests with the part-time BLIS Project Manager (BMA) who is assisted by Assistant Project Managers from each of the other organisations who meet on a periodic basis. This group is responsible for all staffing and administrative activities associated with the Project. The staff of the project are managed on a daily basis by a middle management Thai government official who is responsible for the daily personnel management and technical implementation. The AIDAB technical adviser interacts with all levels of the management structure, but particularly with the Project Manager and the project staff.

This management structure is working effectively within a cooperative environment. In addition to giving technical advice, the Australian advisers are playing a key role of being a catalyst for change within the Royal Thai Government. The role of external advisers in this capacity cannot be over emphasised.

\subsection{Hardware and Software}

As a consequence of the Memorandum of Understanding signed between the participating organisations in 1988, the BMA supervised the development of a project design and a tender specification for the hardware, software, maintenance and training. The BMA had a reasonable idea of the project design as a consequence of the previous pilot projects and the extensive reviews of overseas systems by senior officials. Detailed input to the project design and tender specification was provided by Australian advisers on the TLTP, the present Senior Adviser and vendors. The system went to tender in 1989 and was delivered in early 1990.

The system consists of six (6) high performance SUN graphic workstations, each with a large digitising table, cartridge tape and hard disk drive. Four NEC 386s P.C.'s and printer are also included in the network, as in a laser printer.

The system incorporates a Calcomp colour electrostatic plotter, pen plotter, line printer and dual speed tape drive. The system is connected together via Ethernet cables and has a large Sunserver (3/480) as the main processor/storage device.

System software is based on ESRI's ARC/INFO graphics and database software.

\subsection{Summary of Work Plan}

A detailed work plan has been produced for the duration of the Project which places the major emphasis on the training of the BLIS Project staff in both the design of the system and in the software application development. Recognising that the BLIS Project staff had little prior exposure to this type of technology within their own particular organisations, additional training courses were scheduled with the suppliers of 
the equipment, to supplement the initial system hardware/software related training course. The evaluation and clarification of user needs was a significant activity designed to ensure that the Project staff and senior officials fully understood their organisation's particular Project goals in order that the design of the system reflected these needs.

The close involvement of senior officers from each Organisation was sought in order to place a priority on the various applications of the system in order to focus on the application software development activities.

Regular demonstrations of the development of the system throughout the pilot period have been scheduled, illustrating the importance placed on the exposure of the system to staff from major user areas and senior officials in each participating organisation. This high profile should contribute to the longer term acceptance of BLIS.

The various project activities such as collection and preparation of maps, establishment of data dictionary, development of data input procedures, field checking and verification, etc, have been scheduled in a manner which ensures a full understanding is gained of each component.

\subsection{Progress to date}

The BLIS pilot project commenced in early 1990 and is due for completion in April, 1992. Progress of the project as of February 1991 is set out below.

a. Acquisition of digital base map

A digital base map at 1:1000 of 25 sq.km.has been captured by photogrammetric means using 1:6000 aerial photography flown for the Land Titling Project. Only buildings, street boundaries, canals, manholes and utility poles were obtained. Attribute data consists of house number and building type. The acquisition of this data was much more difficult and slower than anticipated. Random checks have been made to confirm the accuracy of the data.

b. Demonstration of a Prototype Area

A small area of 0.25 sq.km. was selected as a prototype area for the purpose of initial practical training on the system by the Project Staff following the preliminary system training. It also served to illustrate to senior officials some examples of the potential applications of the system at an early stage of the Project. For this demonstration, the major graphical items of each authority, together with samples of associated attribute data, were input onto the digital map base. Project staff have approached the study enthusiastically and were able to produce impressive demonstrations of the system's capabilities to senior officers of their respective organisations during an official opening of the Project three months after the project commenced.

c. Pilot project

For the integration of most utility data sets, a one sq.km. area of the base map was used. This area forms the basis of the demonstration package. Some of the socio-economic data sets are, however, utilising the full 25 sq.km. digital map for the project. Most of the data sets from the participating organisations have been loaded into the system.

d. Demonstration Package

The initial demonstration package has been continually refined as more data is required and put into the system.

e. System Design 
The majority of the system design has been completed and is operating satisfactorily.

\section{f. Symbol and Data Definition}

A lot of effort has gone into the determination and documentation of symbols, data item definition, file structure and size, font libraries and text necessary for inclusion in the data dictionary by each organisation which will provide a basis for the future development of individuals systems. Data input menus requires a lot more development since the software needs considerable "customising" to be able to be used effectively.

\section{g. Data output}

Some graphical output products (plots) have been developed although more will be required as the system is further used. Few reports have been produced in hard copy from the system at this stage due to delays and difficulties in establishing the data base and difficulties in getting the output devices fully operational.

\section{BLIS PROJECT GROUPS}

Although the broad objectives for each of the participating agencies are similar, such as the requirement for education and training, a reliable and accurate common base map and a LIS implementation strategy, each agency has a range of individual objectives and needs a number of specific applications. Specific system applications are currently being identified for each Authority as a better understanding of the system's potential is achieved. A summary of these specific objectives and/or applications is set out below.

\subsection{Metropolitan Electricity Authority (MEA)}

The MEA intends to develop a complete inventory of its network on a graphical base in an effort to improve its services by performing better maintenance and operation of its electrical networks. The Planning Division intends to complete a graphical database which includes the low voltage network and the street light network which are currently not recorded on maps. It is intended that the computer mapping system will also provide input data to existing engineering software packages such as the small area load forecast and the transformer load management packages.

\subsection{Metropolitan Waterworks Authority (MWA)}

Within the MWA, there are three major objectives sought from a system such as BLIS.

a. Establishment of a Network Inventory in order to identify and locate pipe segments and their appurtenances with corresponding house connections and water meters.

b. Short term planning in order to efficiently operate the water supply network and long term planning associated with network analysis, designing future works and evaluating the performance of the existing systems.

c. The ability to enable effective coordination with the other servicing authorities in exchanging reliable map related data on underground and above ground structures and obstacles. This objective is seen as saving considerable time in the planning, designing and upgrading of services.

\subsection{Telephone Organisation of Thailand (TOT)}

The proposed users of the TOT graphical database can be identified broadly as primary and secondary users. The primary or direct users consist of the Division of Outside Engineering who are responsible for updating the map base with the telephone network layers and the Division of Demand Forecasting who also require the above data with additional information about location of cabinets, distribution points, and land and building usage data. Secondary users are Divisions that require data concerning exact locations of buildings, roads, underground and overhead facilities and cadastral parcels. 


\subsection{The Department of Lands (DOL)}

Whilst the DOL is not a user of the proposed products of the BLIS Project, it is however providing the raw data to enable the 1:1,000 scale digital map base to be produced for the pilot area. The staff from DOL working full time on the Project are however, gaining valuable experience utilising the system and experiencing first hand the development of the BLIS on equipment similar to that used within the DOL. The Central Valuation Authority (CVA) within DOL is also contributing data and expertise to the project.

\subsection{Bangkok Metropolitan Administration (BMA)}

As discussed previously, the BMA provides many services throughout Bangkok and as such, the potential applications of an operational BLIS are many and varied. However, the broad objectives of the major user areas are largely as follows:-

\section{a. City Planning Division}

City Planning Division's main objective is to establish and maintain current base map data concerned with land use including building records covering the entire Metropolis.

b. Public Works Department (P.W.D.)

The P.W.D. needs accurate, current building map sheets, an up to date inventory of the road network and existing signboard location and a system which provides coordination and exchange of records with the other utility organisations.

c. Drainage and Sewerage Department

The greatest need for this Department is 'as constructed' drawings and current base map data which facilitates coordination and data exchange with the MWA network.

d. Department of Finance

This department requires current map base/cadastral sheets and current building records in order to correlate the graphic and non graphic data sets as a basis of improving revenue collection.

e. Policy and Planning Department

This department requires access to all of the data stored in a LIS, including a tax database, cadastral file and even the BMA's enterprises with corresponding statistical data.

\section{LESSONS TO DATE}

Even though the BLIS Pilot Project has only completed the first year of a two year program, there are a number of lessons to date from the project, as follows:

a. The cooperative effort between the key land management authorities in the City of Bangkok is proving successful. However it has been essential to give feedback on the project as soon as possible and at regular intervals. In this regard the project organised a comprehensive seminar three months after the equipment was commissioned which proved to be very successful in maintaining the momentum and profile of the project.

b. It was very important that the respective authorities made a significant commitment of money and staff to the project. Without such commitment it may have been difficult to maintain the long term support of the authorities.

c. One of the difficult aspects of the project has been the establishment of an independent Thai Government Unit within the BMA to manage the project. This is a common problem in most 
bureaucracies, especially those in developing countries where there are major financial constraints. However once established, the project has gained a momentum of its own which has been essential for the project's continued development. As in any government organisation worldwide, the establishment of a new office and facilities to support a high technology project with over twenty staff is not easy. The success of this project to date is due to the perseverance of a number of key senior Thai Government officials who fully support and believe in the project.

d. The Australian advisers have had a key role in the establishment of the project, not only for their technical input but also as a catalyst for change. The experience of the full-time adviser has been critical in the success of the project. In addition the regular visits of the Senior Adviser have allowed the project to focus on its performance against the Work Plan on a regular basis. Without the external support for the project, it is unlikely that it would have progressed as planned.

e. A key to the success of the project has been the full support of Thai Government officials at the most senior levels. This support has come from the most senior elected officials as well as the permanent government officers in all the participating authorities. One aspect of this support has been a high level working steering committee which has input from all the participating organisations and which meets regularly. In addition the project has had a number of very senior officials who have "championed" the project from its inception. Without all this support the project would definitely not have commenced or continued.

f. The importance of undertaking a comprehensive pilot project is proving a very worthwhile decision. Already a significant number of directions with regard to identifying a common base map and the appropriate associated indexes, and the methods of capturing and maintaining that data, are becoming evident. The pilot project is certainly confirming the view that the establishment of a comprehensive land information system is not easy and has to overcome many technical, institutional, management and personnel problems.

g. The Thai authorities have taken a long term view of the creation of BLIS as distinct from many LIS initiatives where government's have wanted immediate results and have taken a short term view of the development. The RTG is also placing significant emphasis on the determination of a clear and simple vision for the future. The pilot project will ensure that the vision and the long range plan are reasonably achievable.

h. Already the pilot project has highlighted the very real differences and user needs between digital mapping, land information systems, facility information systems and geographic information systems. At the beginning of the project (and to the present time in some quarters), there was a view that all these systems were basically the same. The project has gone some way to change this view. Simply the user needs and requirements for each of these systems are not the same.

i. The pilot project is highlighting the different needs for education and training. At the operator/technician level there is a requirement for basic training on the system. At the professional level there is a whole range of requirements, generally divided between operation and management of the system. It has proved relatively easy to train officers within a month or so to use the computer system. It will however take a least a year of education to teach the scientific, technical, management and institutional theory underlying the development and operation of LIS/GIS/FIS.

j. One of the most important achievements of the project to date has been the confirmation that the use of a common digital base map is both appropriate and feasible. As in many jurisdictions in both developed and developing countries, there is often the desire by individual organisations to undertake a "quick fix" and to digitise existing maps which are incomplete, inaccurate and incompatible with other authorities. Organisations believe they can manage their own development and computerisation by taking this approach. Unfortunately it is an approach which in the long term results in inefficiencies and greater expense to the general community. This issue is particularly emphasised by Holstein (1990).

$\mathrm{k}$. It is essential that the contract for the hardware and software for the system includes appropriate full-time technical support by the vendor. This ensures that the software will be used appropriately and efficiently thus saving a lot of time and effort of the project personnel.

1. It is essential that an appropriate mechanism is established to ensure that suitable and ongoing policy and technical directions are given by middle management to the usually junior technical staff operating the system. Such direction is very difficult to maintain over the period of the project. This 
has proved to be very difficult in the BLIS project and has been an area which has required continual attention. Some of the solutions are regular technical meetings with middle management, regular demonstrations to middle management and regular publicity of the system.

$\mathrm{m}$. In any project where there are a number of independent organisations such as with BLIS, it must be accepted that different organisations have different priorities, funding sources, objectives and implementation schedules for the long term development of their own systems. It is essential that the Executive and Steering committees manage these different demands to ensure a continued commitment to such basic LIS principles as a common base map. It is very easy for an organisation to believe that "everyone else is too slow" and that they should "do it alone". The importance of keeping the BLIS organisations together has been an important lesson.

n. Continual promotion of the project in the form of seminars, demonstrations, displays and articles is essential in maintaining support for a project such as BLIS.

o. Care must be taken that organisations do not interpret early outputs from the pilot project, such as demonstrations, to infer that the ease of developing a pilot project can be transferred into a permanent institutional system. In reality, pilot projects are relatively easy to develop compared with the development of a permanent institutionalised system. Simply, technology does not solve administrative and institutional LIS problems. Even though the RTG has a long term commitment to the project, it has been important to contain unrealistic expectations from "successful" demonstrations of BLIS.

p. Within the BLIS project it was much easier to establish the technical rather than the administrative infrastructure. Even with a major commitment from the most senior officials it has taken over one year to set up the administrative infrastructure to support the project.

\section{CONCLUSION}

The Bangkok Land Information System Project is proving to be a successful and valuable initiative for all the participating authorities. To date, the strategy to develop a cooperative pilot project between the key land management authorities in Bangkok is proving successful. However, this is not by accident. The Thai authorities have now had numerous LIS/GIS studies over the last five years from countries which have their own successful systems. In the traditional Thai style, the country is learning from the mistakes of others and from the valuable experience of the Land Titling Project to develop a system which will serve the particular needs of the City of Bangkok. While the experiences of the BLIS Project will not be directly applicable to other countries around the world, the project should provide some valuable lessons and experiences.

For many years, the international aid and lending organisations have emphasised rural development projects. There was a view that developing countries could be helped best by improving the agricultural sector. The urban sector was almost ignored. However there is now increasing recognition that the cities are the economic engines of many developing countries. At the same time the problems of these cities are getting worse. This view is now slowly being accepted by the major international bodies. It is recognised that cities have a whole range of different requirements and needs as compared to the rural sector, if their management, quality of life and environment is to improve. It is being recognised in such organisations as the World Bank that land management and in particular land information management is a key factor in improving cities in developing countries. The Bangkok Land Information System is one of the first attempts to resolve some of the desperate problems facing such cities by using land and geographic information systems.

There is no certainty that the BLIS Project will make the planned contribution to an improved management of the City of Bangkok. In order to fully introduce land information management principles across the City would require enormous costs, major institutional changes and a very large education and training program spread over at least ten years. On the other hand there could be very significant economic benefits arriving from such a program. What the project will definitely do, however, is help in determining what is possible and what systems and technologies are applicable. Unfortunately Bangkok and many similar cities do not have a choice; they must explore every possibility and opportunity to 
improve their management. At this point in time land information management offers one of the best hopes.

\section{ACKNOWLEDGEMENTS}

This article describes the Bangkok Land Information System Project. The success of this project to date rests with all the people involved with the project in all the participating authorities and agencies. Particular mention however should be made of Dr Wicha Jiwalai, former Deputy Governor of the BMA, Khun Anuchit Sodsathit, Director General of the Department of Policy and Planning, BMA and Dr Ksemsan Suwarnarat, Project Director. Their continued support and enthusiasm for the project have ensured its success. In addition the assistance of the Australian International Development Assistance Bureau (AIDAB) in supporting the project is recognised.

\section{REFERENCES}

Angus-Leppan, P.V. and I.P.Williamson, 1985. A project for upgrading the cadastral system in Thailand. Survey Review Vol 28/215, 2-14 and Vol 28/216, 63-73.

Angus-Leppan, P.V., 1988. The Thailand Land Titling Project - First steps in a parcel based LIS. International Journal of Geographic Information Systems Vol. 3, No. 1, 59-68.

Holstein, L.C. 1990. Land Information Management in Support of Urban Development in Developing Countries: Requirements, Issues and Options. Discussion Paper. Infrastructure and Urban Development Department, World Bank.

Leppanen, H. 1990. LIS in urban utilities management of Cairo. Proceedings of Commission 3, Congress of the International Federation of Surveyors, Helsinki, 10-19, June, 379-391.

Reyes, C., Negrete, M.E. and C.Payno, 1990. A geo topological information system for the study of the urban structure of Mexico City Metropolitan area. Proceedings of GIS/LIS'90, 7-10 Nov, 1990, Volume 1, 200-208.

Smith, G.L. and L.C.Holstein, 1987. Implementation of the urban mapping system in Thailand. The Australian Surveyor, Vol 33/5, 408-426.

Williamson, I.P. 1983. Cadastral survey techniques in developing countries - with particular reference to Thailand. The Australian Surveyor, Vol 31, No 8, 567-581.

Williamson, I.P. 1990. Considerations in assessing the potential success of a cadastral project in a developing country - A case study of the Thailand Land Titling Project. The Australian Surveyor, Vol 35, No 4, 313-325.

Williamson, I.P. 1991. Land information management at the World Bank. The Australian Surveyor, Vol. 36, No. 1, 41-51.

World Bank. 1989. Urban Management Program - Overview of Program Activities. INURD, February. 


\section{University Library}

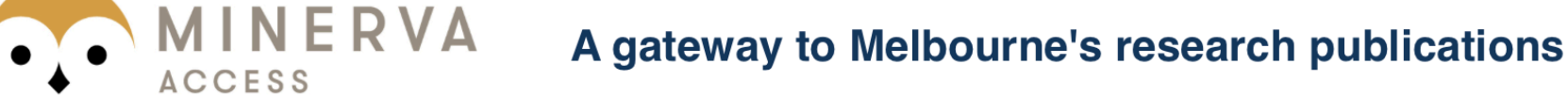

Minerva Access is the Institutional Repository of The University of Melbourne

Author/s:

Williamson, Ian P.;Mathieson, Garry

Title:

The Bangkok Land Information System Project: designing an integrated land information system for a large city in the developing world

Date:

1992

Citation:

Williamson, I. P., \& Mathieson, G. (1992). The Bangkok Land Information System Project: designing an integrated land information system for a large city in the developing world, Canadian Institute of Surveying and Mapping Journal, 46(2), 153-146.

Publication Status:

Published

Persistent Link:

http://hdl.handle.net/11343/34019 